\title{
Fatty acid composition and age estimation of wild Octopus vulgaris paralarvae
}

\author{
D. Garrido a , J.C. Navarro ${ }^{\text {b }}$, C. Perales-Raya a , M. Nande ${ }^{\text {c }}$, M.V. Martín ${ }^{\text {a }}$, J. Iglesias ${ }^{\text {c }}$, A. Bartolomé ${ }^{\text {a }}$, A. Roura ${ }^{\text {d,e }}$, \\ I. Varó ${ }^{\mathrm{b}}$, J.J. Otero ${ }^{\mathrm{c}}$, Á.F. González ${ }^{\mathrm{e}}, \mathrm{C}$. Rodríguez ${ }^{\mathrm{f}}$, E. Almansa ${ }^{\mathrm{a}, *}$ \\ a Centro Oceanográfico de Canarias (IEO), Vía espaldón, Dársena Pesquera PCL 8, 38180 Santa Cruz de Tenerife, Spain \\ ${ }^{\mathrm{b}}$ Instituto de Acuicultura Torre de la Sal (IATS-CSIC), C/Ribera de Cabanes, sn. Cabanes, Castellón, Spain \\ c Centro Oceanográfico de Vigo (IEO), Subida Radio Faro, 50, 362390 Vigo, Pontevedra, Spain \\ d La Trobe University, Kingsbury Drive, Bundoora, 3086 Melboure, Australia \\ e Instituto de Investigaciones Marinas (CSIC), C/Eduardo Cabello, 6, 36208 Vigo, Pontevedra, Spain \\ ${ }^{\mathrm{f}}$ Departamento de Biología Animal, Edafología y Geología (ULL), Av. Astrofisico Fco. Sánchez s/n, 38206 San Cristóbal de La Laguna, Santa Cruz de Tenerife, Spain
}

\section{A R T I C L E I N F O}

\section{Article history:}

Received 18 March 2016

Received in revised form 26 July 2016

Accepted 28 July 2016

Available online 30 July 2016

\section{Keywords:}

Age

Beaks

Fatty acid

Octopus vulgaris

Wild paralarvae

\begin{abstract}
A B S T R A C T
The fatty acid (FA) profile of wild Octopus vulgaris paralarvae of estimated age was individually analyzed for the very first time in order to establish a reference for comparison in rearing and nutritional studies. Age of each paralarvae was estimated by analysing daily increments on lateral hood surface of beaks. Wild paralarvae age ranged between 6 and 8 days and their FA composition resembled that from hatchlings produced under culture conditions. However, when compared with the FA composition of up to 20 days old cultured paralarvae described in the bibliography, some striking differences were found. Results showed higher levels of docosahexaenoic acid (22:6n - 3, DHA), lower contents of $18: 1 n-9,18: 1 n-7$ and $18: 2 n-6$ and negligible levels of $18: 3 n-3$ in wild paralarvae, when collated to reared one. These results seem to indicate that preys/diets supplied to cultured paralarvae fail to resemble paralarval natural composition and as a result do not fulfil their FA requirement. The individual applied technique developed in this study will allow to refine the study of wild paralarvae along its development, as well as to compare wild and cultured paralarvae of similar age.

Statement of relevance: Artemia does not fulfil paralarval fatty acid requirements.
\end{abstract}

(c) 2016 Elsevier B.V. All rights reserved.

\section{Introduction}

The species Octopus vulgaris is an excellent candidate for aquaculture diversification due to its biological and economic features (Iglesias and Fuentes, 2014; Reis et al., 2015). In spite of this fact, rearing O. vulgaris has been particularly difficult due to the total mortalities found during the paralarval stage, which has hampered to close common octopus life cycle under captivity and therefore its commercial production. Based on feeding trials with enriched live food and natural zooplankton, several authors have suggested that this mortality could be caused, in some extent, by nutritional deficiencies of paralarvae (Iglesias and Fuentes, 2014; Navarro et al., 2014; Viciano et al., 2011). Therefore, a better knowledge about nutrition and physiology in wild specimens

Abbreviations: CV, coefficient of variation; DIC, differential interference contrast; DHA, docosahexaenoic acid; DML, dorsal mantle length; EPA, eicosapentaenoic acid; FA, fatty acid; FAME, fatty acid methyl ester; GC, gas chromatography; LC-PUFA, long-chain polyunsaturated fatty acids; LHS, lateral hood surface; MUFA, monounsaturated fatty acids; PCA, principal components analysis; PC1, principal component 1; PC2, principal component 2 .

* Corresponding author.

E-mail address: eduardo.almansa@ca.ieo.es (E. Almansa). could help to ascertain the reasons of the high mortalities shown under culture conditions. However, until now, only a few studies dealt on this specific issue due to difficulties in collecting wild paralarvae. Roura et al. (2012) first identified the natural preys of 0 . vulgaris paralarvae collected in the Ría de Vigo (NW Spain), applying molecular markers and finding preference for decapod crustacean zoeae. However, Artemia (a non decapod crustacean) is the most commonly used prey for rearing octopus paralarvae, and its nutritional composition could lead to differences between wild and reared individuals. In addition, Estefanell et al. (2013) analyzed the fatty acid (FA) profile of newly hatched paralarvae obtained from eggs collected in the wild, finding differences in the FA profile between cultured and wild hatchlings. Nevertheless, to the best of our knowledge, no studies regarding the FA composition have been done from wild individual paralarvae.

A second challenge is the complexity to determine the age of wild specimens, what has hindered the performance of studies focusing on paralarval development. Hernández-López et al. (2001) studied daily formation of growth increments on the lateral walls of the beaks of $O$. vulgaris paralarvae up to 26 days old. Most recently, Perales-Raya et al. (2014) have validated daily deposition in the beak increments of the same species broadening the range of paralarvae and transition-to- 
settlement individuals up to 98 days old, using the lateral hood surface (LHS) of the beak. These findings allow to refine the study of wild paralarvae along their development as well as to compare wild and cultured individuals of similar age.

Under culture conditions, lipid composition and specifically, the FA profile of reared paralarvae is significantly different from hatchlings, one of the most relevant changes being the progressive decrease of docosahexaenoic acid (22:6n - 3, DHA; Arai et al., 2008; Estévez et al., 2009; Fuentes et al., 2011; Iglesias et al., 2014; Navarro and Villanueva, 2000, 2003; Reis et al., 2015, Seixas et al., 2010a, 2010b). These studies point out the lipid composition of Artemia as the major cause of the differences above described since its FA profile seems to be sub-optimal, and may not satisfy paralarval requirements. Moreover, recent studies have shown that 0 . vulgaris has little or no capacity to synthesize long-chain polyunsaturated fatty acids (LC-PUFA), such as DHA, arachidonic acid (20:4n-6, ARA) or eicosapentaenoic acid (20:5n - 3, EPA) and, as a result, these FA are essential and have to be supplied by the diet (Monroig et al., 2013; Reis et al., 2014). However, there is a lack of studies to determine whether these changes could be related to paralarval development rather than to prey or diet composition. Comparison of wild and reared paralarvae of similar age would allow us to elucidate if the changes in FA profile are related with a non-optimal prey composition or are the result of normal development.

The FA profile of paralarvae has always been analyzed in pooled samples (Fuentes et al., 2011; Iglesias et al., 2014; Kurihara et al., 2006; Navarro and Villanueva, 2000, 2003; Okumura et al., 2005; Reis et al., 2015; Seixas et al., 2010a, 2010b; Viciano et al., 2011), hindering the detection of potential differences among individuals. To obtain FA profiles of 0 . vulgaris paralarvae individually, in the present study we have adapted a direct transmethylation method modified from O'Fallon et al. (2007).

Therefore, the aim of this study was to analyze individually, for the very first time, the FA profile of wild Octopus vulgaris paralarvae, and to estimate their age through daily deposition of increments on LHS of the beaks in order to establish a baseline age-FA profile for comparison in nutritional studies of reared paralarvae.

\section{Materials and methods}

\subsection{Sample collection}

Zooplankton samples were collected in the Ría de Vigo (NW Spain) at night between 7th and 8th of October 2013 onboard R/V "Mytilus" (IIM, CSIC). A multinet sampling gear $(0.7 \mathrm{~m} \times 0.7 \mathrm{~m})$ was used to carry out a stratified sampling, collecting samples at the surface, 10 , 20,30 and $40 \mathrm{~m}$ of depth during $10 \mathrm{~min}$ at a speed of $2 \mathrm{kn}$. Ten wild paralarvae were sorted on board from surface samples collected in two stations around Cies Islands. Paralarvae were slaughtered into dry ice and kept at $-80^{\circ} \mathrm{C}$ until their analysis.

\subsection{Length and age of paralarvae}

Dorsal mantle length (DML) of each paralarvae was determined with a stereomicroscopes (Leica MS 5, Leica Microsistemas S.L.U., Barcelona, Spain) prior to beak extraction. Beaks were extracted, cleaned, and preserved in distilled water at approximately $4{ }^{\circ} \mathrm{C}$, according to the procedure of Perales-Raya et al. (2010). Due to the difficulty of the procedure, only 6 beaks of a total of 10 paralarvae were correctly extracted undamaged. Age of paralarvae was estimated reading daily growth increments on LHS of upper beaks according to Perales-Raya et al. (2014), using a transmitted light microscope with Nomarski differential interference contrast (DIC) and 400× magnification (Nikon AZ 100, Tokyo). The DIC system generates a three-dimentional image in which increments are revealed on LHS. Beak reading was performed three times for each paralarvae, being their age estimation the mean value of them. The age precision among readings was assessed with the coefficient of variation (CV; standard deviation divided by the mean number of increments in each sample) (Campana, 2001; Chang, 1982).

\subsection{Fatty acid analysis}

A modification of O'Fallon et al. (2007) method basically based on a downscaling for small amounts of sample was used to analyze the fatty acid methyl ester (FAME) profile of each paralarvae individually without addition of internal standard. The method had been previously tested in hatchlings samples already analyzed by traditional methods (Christie, 1982; Folch et al., 1957). Briefly, each specimen was introduced into a crew capped $2 \mathrm{~mL}$ vial with $70 \mu \mathrm{L}$ of $10 \mathrm{~N} \mathrm{KOH}$ in distilled water plus $660 \mu \mathrm{L}$ of methanol, that was tightly closed. Samples were incubated at $55^{\circ} \mathrm{C}$ during $1.5 \mathrm{~h}$, being shaken during 5 s every 20 min. Then the vial was cooled at room temperature, and $72.5 \mu \mathrm{L}$ of $24 \mathrm{~N}$ $\mathrm{H}_{2} \mathrm{SO}_{4}$ in distilled water were added. Once again the mix was incubated in the conditions above mentioned $\left(55^{\circ} \mathrm{C}\right.$ for $1.5 \mathrm{~h}$, shaking every $20 \mathrm{~min}$ ). After cooling again at room temperature, $187.8 \mu \mathrm{L}$ hexane were added, and the mix was shaken and centrifuged at $2000 \mathrm{~g}$ for 2 min. Finally, the upper hexane layer, which contained the FAME, was transferred to GC vials, evaporated under nitrogen current and redissolved in $300 \mu \mathrm{L}$ of hexane. FA composition was determined using an Agilent 6850 Gas Chromatograph coupled to a 5975 series Mass Selective Detector (MSD, Agilent Technologies, Santa Clara, CA, USA, equipped with a fused silica $30 \mathrm{~m} \times 0.25 \mathrm{~mm}$ open tubular column (Tracer, TR-WAX, film thickness: $0.25 \mu \mathrm{m}$, Teknokroma, Sant-Cugat del Vallés, Spain). Injection of $1 \mu \mathrm{L}$ samples was carried out in splitless mode, using helium as carrier gas $(1.5 \mathrm{~mL} / \mathrm{min}$ constant flow), and a thermal gradient from 50 to $220^{\circ} \mathrm{C}$, and reported in \% of total fatty acids.

\subsection{Data analysis}

Age and FA composition (16:0, 18:0, 18:1n - 9, 18:1n - 7, 18:2n -6, $18: 3 n-3,20: 4 n-6,20: 5 n-3,22: 5 n-3$ and $22: 6 n-3)$ of wild paralarvae, together with hatchlings and reared paralarvae (under or equal to 20 days old) obtained from previous studies (Almansa et al., 2012, Navarro and Villanueva, 2000, 2003; Reis et al., 2015; Seixas et al., 2010a, 2010b; Socorro et al., 2004) were analysed by principal components analysis (PCA). Factor scores from PCA were checked for normal distribution with the one-sample Kolmogorov-Smirnoff test, as well as, for homogeneity of the variances with the Levene's test (Zar, 1999), and transformed by arcsine when needed (Fowler et al., 1998). After that, one-way ANOVA followed by a Tukey's post hoc test (Zar, 1999) was assessed. When normal distribution and/or homoscedasticity were not achieved, data were subjected to Kruskall-Wallis non-parametric test, followed by Games-Howell non-parametric multiple comparison test (Zar, 1999). The FA with striking differences among wild, hatchlings and culture paralarvae $(18: 1 n-9,18: 1 n-7$, $18: 2 n-6,18: 3 n-3$ and $22: 6 n-3)$ were also analyzed by one-way ANOVA following the procedure described above. Statistical analyses were carried out using SPSS for Windows 15.0 statistical package (SPSS Inc., Chicago, IL, USA).

\section{Results and discussion}

The FA composition of the age-estimated wild Octopus vulgaris paralarvae was achieved individually. It was only possible in 10 specimens, since collecting of wild paralarvae presents serious difficulties in terms of getting a reasonable number of individuals mainly due to their dispersion patterns, linked to marine dynamics, and their possible vertical migration (Otero et al., 2009). Some studies focused on prey identification and microbiome (Roura et al., 2012, 2015) as well as nutritional composition (Lourenço, 2014) have been also carried out recently in wild paralarvae, however, in these studies the age of the paralarvae was unknown, so accurate comparisons with reared paralarvae could not be performed. In addition, the analysis of 
Lourenço (2014) was conducted in paralarvae pools, which hampers the characterization of natural variability of the paralarvae.

The average age of these paralarvae, estimated through daily deposition of increments on LHS beaks, was $7 \pm 1$ days. The youngest specimens were 6 days old and the oldest 8 days old (Table 1), although only 6 beaks were readable from a total of 10 wild paralarvae due to damages suffered by the beaks during the dissection. This technique for age estimation has also been successfully used in reared 0 . vulgaris paralarvae by Franco-Santos et al. (2015). An alternative tool for age estimation could be the growth equations based on dorsal mantle length (DML) obtained by Villanueva (1995) and Carrasco et al. (2006). In the present study, average DML of wild paralarvae was $2.47 \pm$ $0.23 \mathrm{~mm}$ (minimum: $2.07 \mathrm{~mm}$ and maximum: $2.88 \mathrm{~mm}$ ) (Table 1). Thus, age estimations of wild paralarvae according to the growth equation reported by Villanueva (1995) ranged between 2 and 15 days old. Similarly, using the growth equation reported by Carrasco et al. (2006), the age of the wild paralarvae ranged between 2 and 12 days old, showing high data dispersion, indeed two individuals (Table 1, case 6 and 8) showed negative values using this equation. In contrast, the results obtained by reading growth marks in the beaks were more accurate, avoiding negative values (e.g. case 6 was estimated as 6 days old paralarva).

The lack of accuracy in age estimation detected when using growth equation estimations could be related to differences in environmental factors such as temperature, which has a strong influence on the growth of cephalopods (Boletzky, 2003; Pecl et al., 2004). It must be taken into account that those equations have been optimized under controlled conditions, which probably differ from environmental conditions in the wild. In addition, paralarval length is determined by initial length of hatchlings (Pecl et al., 2004), but a high variability has been usually observed in the length of hatched paralarvae (Arai et al., 2008; Carrasco et al., 2006; Itami et al., 1963; Seixas et al., 2010a, 2010b; Villanueva, 1995). These differences seem to be related to several factors such as incubation temperature (Repolho et al., 2014; Vidal et al., 2002) or broodstock diets (Quintana et al., 2015), but other causes such as shrinkage due to the storage condition, population origin or female condition cannot be discarded. Consequently, equation estimations seem to be not as accurate for wild paralarvae age estimation, as beak reading is.

FA composition of 10 wild 0 . vulgaris paralarvae is shown in Table 1. Palmitic acid (16:0) and stearic acid (18:0) were the most abundant saturated fatty acids, oleic acid $(18: 1 n-9)$ and gondoic acid $(20: 1 n-9)$ were the most representative fatty acids among monoenes, and the most abundant LC-PUFA: ARA, EPA and DHA, showing the DHA the highest value among all.

A principal component analysis (PCA) was used to examine the multivariate structure of the FA profile of wild paralarvae of estimated age in comparison with hatchlings and reared paralarvae aged 20 days or less obtained from previous studies (Tables 2 and 3, Fig. 1). Both components of PCA considered in this analysis (PC1 and PC2) accounted $63.88 \%$ of variation. PC1 explained $47.40 \%$ of the variation, being $18: 1 n-9,18: 1 n-7,18: 2 n-6$ and $22: 6 n-3$ the fatty acids that

Table 1

Dorsal mantle length (DML, in mm), age (days), age coefficient variation (CV, as \%) and fatty acid composition (\% of total fatty acids) of wild Octopus vulgaris paralarvae.

\begin{tabular}{|c|c|c|c|c|c|c|c|c|c|c|c|}
\hline Paralarva & 1 & 2 & 3 & 4 & 5 & 6 & 7 & 8 & 9 & 10 & \\
\hline DML & 2.55 & 2.88 & 2.55 & 2.38 & 2.52 & 2.19 & 2.62 & 2.07 & 2.59 & 2.38 & $2.47 \pm 0.23$ \\
\hline Age & 7 & & & 7 & 8 & 6 & 8 & & & 7 & $7 \pm 1$ \\
\hline $\mathrm{CV}$ & 10.9 & & & 25.5 & 0.0 & 9.1 & 0.0 & & & 0.0 & \\
\hline \multicolumn{12}{|l|}{ Fatty acids } \\
\hline $14: 0$ & 1.36 & 1.20 & 0.97 & 0.53 & 1.03 & 1.29 & 0.94 & 1.73 & 1.25 & 1.13 & $1.14 \pm 0.31$ \\
\hline $15: 0$ & 0.18 & 0.38 & nd & nd & nd & 0.33 & 0.28 & 0.29 & 0.42 & 0.46 & $0.33 \pm 0.09$ \\
\hline $16: 0$ & 23.56 & 21.57 & 23.24 & 21.80 & 21.03 & 19.85 & 20.81 & 21.23 & 18.79 & 18.73 & $21.06 \pm 1.63$ \\
\hline $16: 1 n-9$ & 0.38 & 0.26 & nd & nd & nd & 0.37 & 0.12 & 0.31 & 0.38 & 0.39 & $0.32 \pm 0.10$ \\
\hline $16: 1 n-7$ & 0.32 & 1.02 & 0.14 & nd & nd & 0.96 & 0.63 & 0.35 & 0.97 & 0.60 & $0.63 \pm 0.34$ \\
\hline $16: 1 n-5$ & nd & nd & nd & nd & nd & nd & nd & nd & 0.21 & 0.18 & $0.20 \pm 0.02$ \\
\hline $17: 0$ & 1.25 & 1.72 & 1.65 & 1.62 & 1.76 & 1.10 & 1.26 & 0.98 & 1.22 & 1.35 & $1.39 \pm 0.28$ \\
\hline $18: 0$ & 13.46 & 11.86 & 14.25 & 14.10 & 11.17 & 10.76 & 9.95 & 10.17 & 10.21 & 10.35 & $11.63 \pm 1.70$ \\
\hline $18: 1 n-13$ & 0.93 & 0.73 & 0.88 & 0.44 & 0.91 & 0.94 & 0.41 & 0.56 & 0.99 & 1.03 & $0.78 \pm 0.23$ \\
\hline $18: 1 n-9$ & 3.67 & 2.98 & 2.07 & 3.48 & 1.84 & 2.76 & 1.43 & 1.66 & 2.63 & 2.49 & $2.50 \pm 0.75$ \\
\hline $18: 1 n-7$ & 1.49 & 2.06 & 1.36 & 2.18 & 1.04 & 2.09 & 1.42 & 1.52 & 2.36 & 1.58 & $1.71 \pm 0.56$ \\
\hline $18: 1 n-5$ & nd & nd & nd & nd & nd & nd & nd & nd & 0.20 & 0.19 & $0.20 \pm 0.01$ \\
\hline $18: 2 n-6$ & 1.47 & 0.24 & nd & nd & 0.17 & 0.46 & nd & nd & 0.37 & 0.39 & $0.52 \pm 0.48$ \\
\hline $18: 3 n 3$ & nd & nd & nd & nd & nd & nd & nd & nd & 0.18 & nd & 0.18 \\
\hline $18: 4 n-3$ & nd & 0.16 & nd & nd & nd & nd & nd & nd & 0.25 & 0.17 & $0.19 \pm 0.05$ \\
\hline $20: 1 n-11$ & 0.17 & 0.30 & nd & nd & nd & 0.37 & 0.09 & 0.15 & 0.41 & 0.37 & $0.27 \pm 0.13$ \\
\hline $20: 1 n-9$ & 4.27 & 4.01 & 5.55 & 3.97 & 3.61 & 3.04 & 2.69 & 3.44 & 2.99 & 3.28 & $3.69 \pm 0.83$ \\
\hline $20: 1 n-7$ & nd & 0.05 & nd & nd & nd & 0.23 & nd & nd & 0.37 & 0.19 & $0.21 \pm 0.13$ \\
\hline $20: 2 n-6$ & 0.27 & 0.54 & nd & nd & nd & 0.52 & nd & nd & 0.68 & 0.58 & $0.52 \pm 0.15$ \\
\hline $20: 4 n-6$ & 2.35 & 3.56 & 4.69 & 2.91 & 2.79 & 4.91 & 2.58 & 5.17 & 4.13 & 2.52 & $3.56 \pm 1.08$ \\
\hline $20: 3 n-3$ & 0.78 & 1.29 & 0.91 & 0.20 & 0.69 & 1.15 & 0.76 & 0.58 & 0.94 & 1.02 & $0.83 \pm 0.31$ \\
\hline $20: 5 n-3$ & 13.98 & 14.07 & 16.19 & 16.64 & 20.85 & 23.52 & 24.22 & 20.22 & 19.32 & 22.36 & $19.14 \pm 3.75$ \\
\hline $22: 5 n-3$ & 0.42 & 0.71 & nd & 0.26 & 0.39 & 4.40 & 0.71 & 0.85 & 1.17 & 1.43 & $1.15 \pm 1.28$ \\
\hline $22: 6 n-3$ & 28.93 & 28.01 & 27.62 & 31.18 & 30.34 & 17.04 & 29.08 & 26.91 & 26.21 & 25.30 & $27.06 \pm 3.95$ \\
\hline UK & 0.76 & 3.28 & 0.49 & 0.70 & 2.38 & 3.90 & 2.62 & 3.89 & 3.33 & 3.89 & $2.52 \pm 1.39$ \\
\hline SFA & 39.81 & 36.73 & 40.11 & 38.04 & 34.99 & 33.33 & 33.24 & 34.39 & 31.90 & 32.02 & $35.46 \pm 3.06$ \\
\hline MUFA & 11.22 & 11.41 & 10.01 & 10.07 & 7.40 & 10.77 & 6.80 & 7.99 & 11.52 & 10.31 & $9.75 \pm 1.73$ \\
\hline PUFA & 48.20 & 48.58 & 49.39 & 51.19 & 55.23 & 52.00 & 57.34 & 53.73 & 53.25 & 53.78 & $52.27 \pm 2.97$ \\
\hline$n-3$ & 44.11 & 44.23 & 44.71 & 48.28 & 52.26 & 46.12 & 54.76 & 48.56 & 48.07 & 50.28 & $48.14 \pm 3.54$ \\
\hline$n-6$ & 4.10 & 4.34 & 4.69 & 2.91 & 2.97 & 5.89 & 2.58 & 5.17 & 5.18 & 3.50 & $4.13 \pm 1.12$ \\
\hline LC-PUFA $n-3$ & 44.11 & 44.07 & 44.71 & 48.28 & 52.26 & 46.12 & 54.76 & 48.56 & 47.64 & 50.11 & $48.06 \pm 3.56$ \\
\hline$n-3 / n-6$ & 10.76 & 10.19 & 9.54 & 16.60 & 17.63 & 7.83 & 21.25 & 9.40 & 9.28 & 14.37 & $12.69 \pm 4.49$ \\
\hline DHA/EPA & 2.07 & 1.99 & 1.71 & 1.87 & 1.46 & 0.72 & 1.20 & 1.33 & 1.36 & 1.13 & $1.48 \pm 0.43$ \\
\hline EPA/ARA & 5.94 & 3.95 & 3.45 & 5.72 & 7.46 & 4.79 & 9.40 & 3.91 & 4.68 & 8.86 & $5.82 \pm 2.11$ \\
\hline DHA/ARA & 12.29 & 7.86 & 5.89 & 10.72 & 10.86 & 3.47 & 11.28 & 5.21 & 6.35 & 10.02 & $8.40 \pm 3.03$ \\
\hline
\end{tabular}

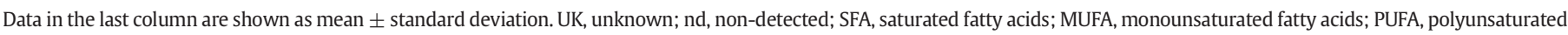
fatty acids; LC-PUFA, long-chain polyunsaturated fatty acids; DHA, 22:6n - 3; EPA, 20:5n-3; ARA, 20:4n -6. 
Table 2

Fatty acid composition (\% of total fatty acids) of 0 . vulgaris hatchlings obtained under captivity from different studies.

\begin{tabular}{|c|c|c|c|c|c|c|c|c|c|c|}
\hline References & $16: 0$ & 18:0 & $18: 1 n-9$ & $18: 1 n-7$ & $18: 2 n-6$ & $18: 3 n-3$ & $20: 4 n-6$ & $20: 5 n-3$ & $22: 5 n-3$ & $22: 6 n-3$ \\
\hline Almansa et al. (2012) & 17.97 & 9.26 & 2.69 & 1.40 & 0.68 & 0.06 & 5.02 & 17.45 & 1.30 & 24.89 \\
\hline Reis et al. (2015) & 21.05 & 9.40 & 2.06 & 1.08 & 0.44 & nd & 4.56 & 17.07 & 1.14 & 26.45 \\
\hline Navarro and Villanueva (2000) & 17.50 & 6.30 & 4.00 & 1.60 & 3.30 & nd & 7.30 & 12.60 & 1.70 & 21.20 \\
\hline Seixas et al. (2010b) & 28.00 & 12.10 & 3.40 & 1.80 & 0.70 & nd & 3.40 & 14.50 & 1.50 & 19.50 \\
\hline Seixas et al. (2010a) & 20.30 & 15.50 & 3.00 & 1.80 & 1.20 & nd & 6.60 & 13.40 & 2.20 & 20.30 \\
\hline Socorro et al. (2004) & 20.16 & 12.96 & 1.86 & 2.99 & 0.93 & 0.22 & 6.28 & 11.26 & 0.00 & 17.26 \\
\hline Mean \pm SD & $20.83 \pm 3.78$ & $10.92 \pm 3.25$ & $2.84 \pm 0.81$ & $1.78 \pm 0.65$ & $1.21 \pm 1.06$ & $0.14 \pm 0.11$ & $5.53 \pm 1.45$ & $14.38 \pm 2.47$ & $1.31 \pm 0.74$ & $21.60 \pm 3.45$ \\
\hline
\end{tabular}

Data in the last row correspond to the mean \pm standard deviation (SD) from the studies included in the table. nd, non-detected.

showed higher contribution. PC1 clearly separated fatty acids that predominate in reared paralarvae, $18: 1 n-9,18: 1 n-7$ and $18: 2 n-6$ (on the right) from those more abundant in wild and hatchling paralarvae as $22: 6 n-3$ (on the left). PC2 accounted for a smaller percentage of variability (16.48\%) with the highest weighting for fatty acids 18:0 and $18: 3 n-3$ both above the zero line (Fig. $1 \mathrm{~A}$ ).

The graphical distribution of individual factor scores of paralarvae labelled with its age is shown in Fig. 1B. A one-way ANOVA test was used to compare wild, hatchlings and reared paralarvae scores. Results showed significant differences for factor score $1(P<0.05)$ with a significant separation of wild and hatchling paralarvae from reared paralarvae (represented as separated ellipses in Fig. 1B). Also when factor score distribution is examined in reared paralarvae, apparently, a certain degree of stratification according to age exists, being younger reared individuals closer to hatchlings and wild paralarvae group (Fig. 1B). In this comparison, differences due to the analysis method have been discarded because our method has been successfully compared with the methods used in the previous studies (Tables 2 and 3). The differences observed between groups could be associated to divergence in the diet consumed, because wild paralarvae are specialist predators mainly feeding on decapod crustacean zoeae independently of the zooplankton community they inhabit (Roura et al., 2012, 2016), while cultured paralarvae are usually fed with Artemia and/or other alternative preys suboptimally (Almansa et al., 2012; Navarro and Villanueva, 2000, 2003; Reis et al., 2015; Seixas et al., 2010a, 2010b; Socorro et al., 2004; Viciano et al., 2011).

This differentiation between hatchlings-wild group and reared paralarvae is mainly explained by differences in the relative proportions of DHA, $18: 3 n-3,18: 1 n-9,18: 1 n-7$ and 18:2n-6, being DHA the most striking one. Clearly, diet supplied to cultured paralarvae does not seem to cover properly their DHA requirements as suggested by Navarro and Villanueva (2000), since wild paralarvae showed an average of $27.06 \pm 3.95 \%$ of DHA, while cultured paralarvae from the studies incorporated in PCA display significantly $(P<0.001)$ much lower values $(10.44 \pm 3.57 \%$ of DHA, Table 3$)$. This drop in DHA suggests that even the enriched Artemia do not fulfil the paralarvae needs since such a drop is not reflected by the wild paralarvae. In fact, only Okumura et al. (2005) reported similar DHA values $(27.26 \pm 1.76 \%)$ in 32 days old

Table 3

Fatty acid composition (\% of total fatty acids) of reared 0 . vulgaris paralarvae at different ages (days) obtained from different studies.

\begin{tabular}{|c|c|c|c|c|c|c|c|c|c|c|c|c|}
\hline References & Diet & Age & $16: 0$ & $18: 0$ & $18: 1 n-9$ & $18: 1 n-7$ & $18: 2 n-6$ & $18: 3 n-3$ & $20: 4 n-6$ & $20: 5 n-3$ & $22: 5 n-3$ & $22: 6 n-3$ \\
\hline \multirow[t]{3}{*}{ Almansa et al. (2012) } & GRA & \multirow[t]{3}{*}{15} & 16.35 & 12.13 & 6.83 & 2.63 & 1.75 & 0.30 & 12.60 & 11.19 & 1.16 & 16.80 \\
\hline & ART-N & & 14.28 & 12.48 & 11.60 & 4.83 & 3.04 & 7.66 & 3.36 & 13.71 & 0.64 & 9.91 \\
\hline & ART-J & & 15.82 & 13.50 & 8.88 & 5.72 & 2.86 & 5.82 & 3.92 & 16.62 & 0.74 & 8.89 \\
\hline \multirow[t]{3}{*}{ Reis et al. (2015) } & GRA & \multirow[t]{3}{*}{9} & 19.64 & 12.16 & 6.31 & 3.29 & 1.76 & 0.71 & 12.62 & 12.00 & 1.09 & 14.36 \\
\hline & PAL:ART & & 19.18 & 11.51 & 5.26 & 3.99 & 1.32 & 1.42 & 6.34 & 16.29 & 0.85 & 17.80 \\
\hline & ART-J & & 17.50 & 13.78 & 5.96 & 3.63 & 1.79 & 2.77 & 4.75 & 17.11 & 0.00 & 15.29 \\
\hline \multirow{12}{*}{$\begin{array}{l}\text { Navarro and Villanueva } \\
\text { (2003) }\end{array}$} & AN10 & \multirow[t]{4}{*}{10} & 17.90 & 9.80 & 13.40 & 8.50 & 2.00 & 0.70 & 2.50 & 8.10 & 0.60 & 8.70 \\
\hline & MC1 & & 16.60 & 9.10 & 13.00 & 8.40 & 2.10 & 0.80 & 2.80 & 8.30 & 0.60 & 8.70 \\
\hline & MC2 & & 14.70 & 8.70 & 13.00 & 8.10 & 3.20 & 1.70 & 3.40 & 11.60 & 0.80 & 8.10 \\
\hline & MC3 & & 15.20 & 8.70 & 12.70 & 8.30 & 2.80 & 1.40 & 2.90 & 10.90 & 0.80 & 8.20 \\
\hline & AN10 & \multirow[t]{4}{*}{15} & 17.30 & 10.10 & 14.10 & 8.80 & 2.00 & 0.80 & 2.60 & 7.70 & 0.60 & 7.20 \\
\hline & MC1 & & 16.10 & 9.50 & 14.20 & 9.10 & 1.80 & 0.70 & 2.60 & 7.20 & 0.60 & 7.30 \\
\hline & MC2 & & 13.70 & 8.50 & 13.80 & 8.60 & 3.20 & 1.80 & 3.20 & 13.00 & 0.80 & 7.10 \\
\hline & MC3 & & 13.20 & 8.20 & 14.30 & 9.00 & 3.30 & 1.80 & 3.00 & 12.30 & 0.80 & 6.60 \\
\hline & AN10 & \multirow[t]{4}{*}{20} & 16.50 & 10.70 & 13.50 & 8.70 & 2.50 & 1.20 & 3.20 & 9.90 & 0.70 & 6.70 \\
\hline & MC1 & & 16.70 & 10.10 & 13.30 & 8.50 & 2.00 & 0.70 & 2.80 & 8.10 & 0.70 & 6.80 \\
\hline & MC2 & & 12.50 & 8.00 & 13.30 & 8.40 & 3.60 & 2.10 & 3.20 & 16.10 & 0.90 & 6.70 \\
\hline & MC3 & & 13.90 & 8.60 & 15.10 & 9.10 & 4.00 & 2.20 & 3.40 & 9.30 & 0.80 & 5.10 \\
\hline \multirow[t]{6}{*}{ Seixas et al. (2010b) } & ArDHA & \multirow[t]{3}{*}{10} & 25.20 & 13.50 & 6.20 & 5.10 & 1.60 & 1.10 & 3.80 & 14.20 & 1.10 & 14.40 \\
\hline & ArMA & & 25.70 & 14.60 & 3.10 & 5.00 & 0.80 & 2.50 & 2.30 & 16.00 & 1.40 & 14.50 \\
\hline & $\begin{array}{l}\text { ArMA + } \\
\text { ID }\end{array}$ & & 26.50 & 14.60 & 3.30 & 4.90 & 0.80 & 2.10 & 3.30 & 15.40 & 1.20 & 13.70 \\
\hline & ArDHA & \multirow[t]{3}{*}{15} & 23.10 & 14.60 & 8.10 & 6.60 & 2.10 & 2.10 & 3.50 & 14.60 & 0.90 & 12.60 \\
\hline & ArMA & & 23.00 & 17.40 & 3.60 & 8.00 & 0.80 & 3.60 & 2.80 & 16.40 & 1.10 & 10.60 \\
\hline & $\begin{array}{l}\text { ArMA + } \\
\text { ID }\end{array}$ & & 22.80 & 16.90 & 3.60 & 8.30 & 0.90 & 3.90 & 2.90 & 17.60 & 0.80 & 9.90 \\
\hline \multirow[t]{3}{*}{ Seixas et al. (2010a) } & $\mathrm{AR}+\mathrm{I}$ & \multirow[t]{4}{*}{15} & 14.50 & 15.10 & 7.10 & 4.90 & 3.30 & 5.20 & 3.10 & 18.30 & 1.10 & 9.80 \\
\hline & AGOLD & & 14.50 & 14.60 & 7.70 & 4.80 & 4.00 & 4.10 & 3.80 & 16.30 & 1.20 & 13.60 \\
\hline & AGOPEL & & 15.60 & 15.00 & 7.70 & 5.30 & 3.50 & 4.30 & 3.50 & 16.30 & 1.10 & 12.40 \\
\hline Mean \pm SD & & & $\begin{array}{l}17.70 \pm \\
4.06\end{array}$ & $\begin{array}{l}11.92 \pm \\
2.85\end{array}$ & $\begin{array}{l}9.59 \pm \\
4.10\end{array}$ & $\begin{array}{l}6.68 \pm \\
2.12\end{array}$ & $\begin{array}{l}2.33 \pm \\
0.99\end{array}$ & $\begin{array}{l}2.35 \pm \\
1.81\end{array}$ & $\begin{array}{l}4.01 \pm \\
2.60\end{array}$ & $\begin{array}{l}13.13 \pm \\
3.50\end{array}$ & $\begin{array}{l}0.85 \pm \\
0.28\end{array}$ & $\begin{array}{l}10.44 \pm \\
3.57\end{array}$ \\
\hline
\end{tabular}

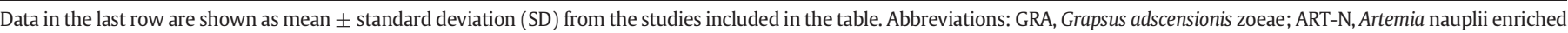

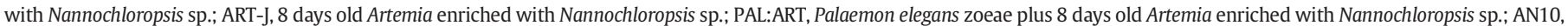

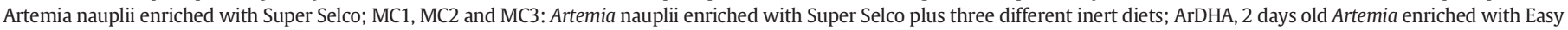

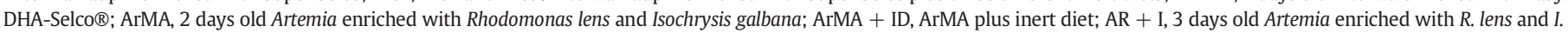
galbana; AGOLD, 3 days old Artemia enriched with Ori-Gold®; AGOPEL, AGOLD plus a inert diet. 

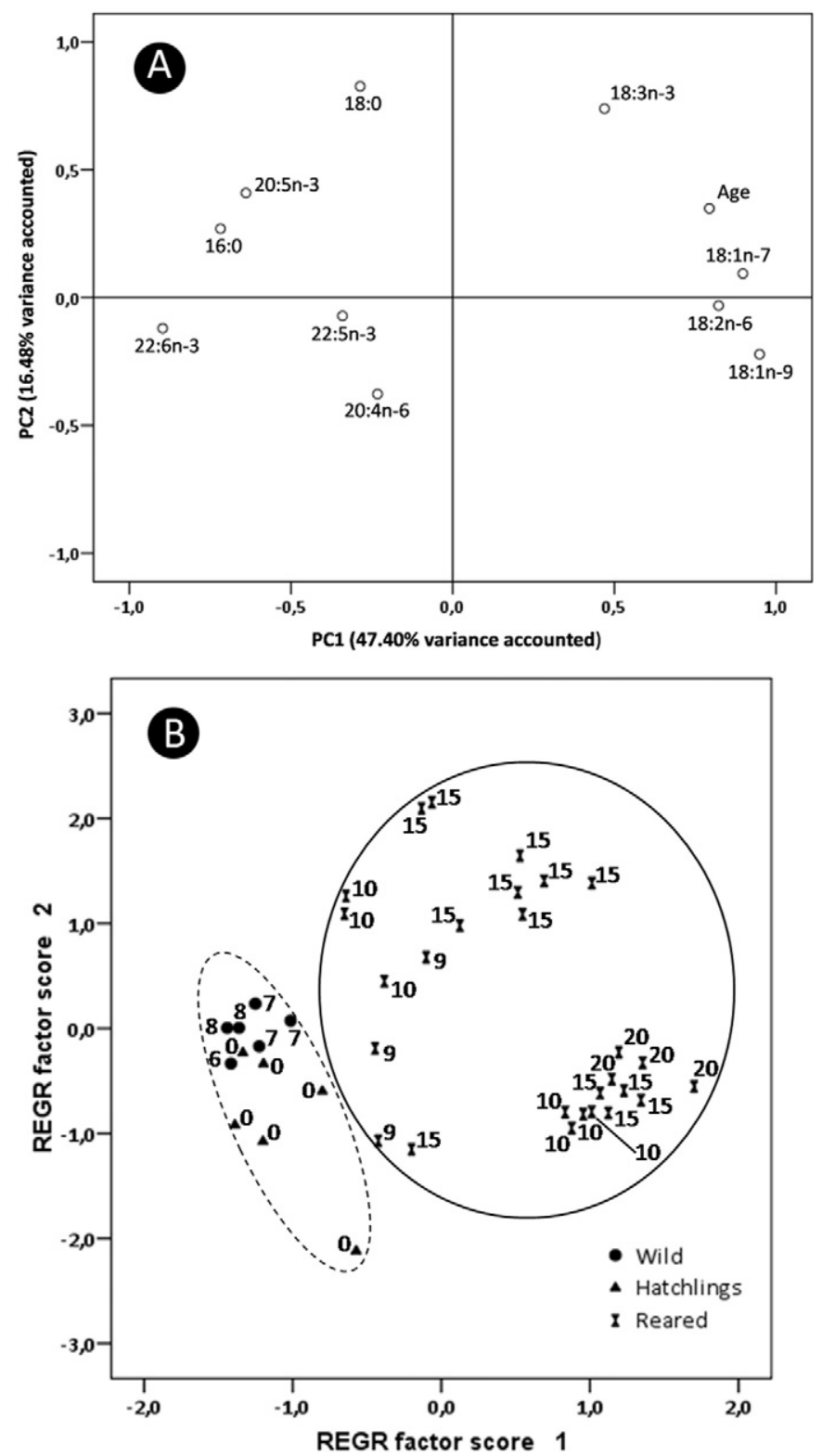

Fig. 1. Principal component analysis (PCA) of fatty acids (\% of total fatty acids) and age (days) from wild, hatchlings and reared Octopus vulgaris paralarvae. (A) Factor loading plot for principal component 1 (PC1) and principal component 2 (PC2) (B) Factor score plot. Labels associated to individual scores in plot B indicate the age. Ellipses represent different clusters for PC1 according to ANOVA results.

cultured paralarvae when feeding them with Artemia plus frozen flakes of the fish Ammodytes personatus. Apparently, the inclusion of fish in the diet improved the DHA content in paralarvae. However, subsequent studies were unable to replicate these results despite using the same A. personatus flakes: Arai et al. (2008) obtained a DHA level between 6.8 and $10.5 \%$ in 25 days old paralarvae, whereas Kurihara et al. (2006) obtained values between 13.5 and $16.5 \%$ in 42 days old paralarvae. In consequence, further studies are necessary to clarify these differences.

Feature of Artemia and octopus FA metabolism may explain the drop in DHA observed in culture paralarvae. On one hand, Artemia is known to catabolise DHA through both retroconversion and $\beta$-oxidation (Navarro et al., 1999) and also accumulate this FA as triacylglycerides (Guinot et al., 2013; Navarro et al., 1999) diminishing its bio-availability. On the other hand, Octopus vulgaris lack of $\Delta 4$ desaturases, and $\Delta 6$ desaturases which hampers DHA biosynthesis from $22: 5 n-3$ as well through an elongation of $22: 5 n-3$ to $24: 5 n-3$ and subsequent desaturation to 24:6n - 3 and final chain-shortening (Monroig et al., 2013; Reis et al., 2014). Very recently studies highlight a competition between DHA and $18: 3 n-3$ for esterification into octopus PC. Artemia is particularly rich in this $\mathrm{C}_{18}$ FA which may also hamper the DHA reacylation into phospholipids (Reis et al., 2014). A deeper understanding of octopus paralarvae lipid metabolism and new and more efficient methods of Artemia enrichment are still needed to overcome DHA bioavailabilty.

The levels of $18: 3 n-3$ in wild paralarvae were negligible (when detected), being present in just one of the paralarvae analyzed at levels only of $0.18 \%$ (Table 1 ). This FA is not detected in hatchlings from reared broodstock (Arai et al., 2008; Kurihara et al., 2006; Navarro and Villanueva, 2000; Reis et al., 2015; Seixas et al., 2010a, 2010b), or it is found in very low proportions (Almansa et al., 2012; Okumura et al., 2005; Socorro et al., 2004). However, this FA appears to increase considerably its value in cultured individuals $(P=0.003)$, reaching mean values of $2.35 \pm 1.81 \%$ (Table 3 ), which represents a 16.8 fold increase through paralarvae development (Table 2 and 3 ). Considering this fact, the diet supplied to reared paralarvae seems to be the origin of the differences observed in 18:3n - 3, since Artemia displays high levels of this FA (Navarro et al., 1993). However, it must be taken into account that within Artemia the levels of 18:3n -3 differ between strains. Two main groups can be identified: one rich in 18:3n-3, but poor in EPA (freshwater type), and a second one with high percentages of EPA but low $18: 3 n-3$ (usually known as highly LC-PUFA Artemia or marine type) (Watanabe et al., 1978, 1980). In the light of these results, the "highly LC-PUFA Artemia" seems to be more appropriate than "freshwater type", although the suitability of both Artemia strains in the 0 . vulgaris paralarvae culture should be re-considered in future studies. Finally, Reis et al. (2014) did not detect in O. vulgaris paralarvae EPA synthesis from 18:3n-3, although increments in the levels of EPA from $20: 4 n-3$ has been reported by (Monroig et al., 2013), therefore this FA must be supplied in the diet of paralarvae.

Regarding to monoenes, although $18: 1 \mathrm{n}-9$ and $18: 1 \mathrm{n}-7$ were found in all paralarvae analyzed, the levels of both fatty acids seemed to be higher $(P<0.001)$ in reared individuals $(18: 1 \mathrm{n}-9$ : $9.59 \pm 4.10 \%$ and $18: 1 \mathrm{n}-7: 6.68 \pm 2.12 \%$, Table 3$)$ than in hatchlings $(18: 1 \mathrm{n}-9$ : $2.84 \pm 0.81 \%$ and $18: 1 \mathrm{n}-7: 1.78 \pm 0.65 \%$, Table 2 ) and wild paralarvae $(18: 1 \mathrm{n}-9: 2.50 \pm 0.75 \%$ and $18: 1 \mathrm{n}-7: 1.71 \pm 0.56 \%$, Table 1$)$. Thereby, the higher accumulation of $18: 1 n-9$ and $18: 1 n-7$ in cultured individuals may be also associated to the Artemia profile. In fact, Reis et al. (2014) found that $18: 1 \mathrm{n}-9$ is accumulated by paralarvae in neutral lipid fraction especially in triacylglycerols.

The $18: 2 n-6$ is precursor of ARA in fish. Nonetheless in cephalopods there are not $\Delta 6$ or $\Delta 8$ desaturase activities able to synthesis ARA (Monroig et al., 2013), although transformations of $18: 2 n-6$ to 20:2n-6 and 22:2n-6 have been observed by Reis et al. (2014) in 0 . vulgaris paralarvae. With respect to $18: 2 n-6$, wild paralarvae showed an average value of $0.52 \pm 0.48 \%$, this FA being absent in some of them. These values were similar $(P=0.197)$ to those observed in hatchlings $(1.21 \pm 1.06 \%$, Table 2$)$ but significantly lower $(P<0.001)$ than cultured paralarvae $(2.33 \pm 0.99 \%$, Table 3$)$. These differences are less prominent than other FA discussed above in this section, but could also be related to the diet supplied to cultured paralarvae as this polyunsaturated fatty acids (PUFA) accounts for around 4-5\% of enriched Artemia FA profile (Navarro et al., 1993). However, there are not enough evidences to discuss whether this fact may be relevant for paralarvae development.

\subsection{Conclusions}

In summary, the age estimation method based on daily growth increments in the beak of $O$. vulgaris is a useful tool for comparative studies using wild specimens along their development, as well as a tool to compare wild and cultured paralarvae of similar age. In the present study, we have characterized the FA composition of wild individual paralarvae, which is quite similar to that observed in hatchlings, but 
significantly different from cultured individuals. Our results suggest that the preys or diets supplied to the cultured specimens have a FA composition that does not fulfil their nutritional requirements. Higher levels of DHA, lower contents of $18: 1 n-9,18: 1 n-7$ and $18: 2 n-6$ and negligible levels of $18: 3 n-3$ in wild paralarvae, seemed to be the main responsible players in the differentiation between wild and cultured paralarvae and should be considered of special relevance to design an Artemia enrichment or artificial diet that allows to enhance and further improve paralarvae rearing protocols.

\section{Acknowledgements}

This study was funded by Spanish Government under Projects OCTOPHYS (Ref. AGL2010-22120-C03), OCTOWELF (Ref. AGL201349101-C2-1-R) and LARECO (CTM2011-25929). Most of the authors of this paper participate to the COST network, Action FA1301 (CephsInAction) focussing on Cephalopod welfare. D. Garrido was financed by a Ph.D. grant by Spanish Institute of Oceanography (BOE 3rd November 2011). We thank Dr. Deiene Rodríguez Barreto for her useful revision and assistance with clarification of the manuscript. We thank the collaboration of Parque Nacional das Illas Atlanticas (Galicia, Spain).

\section{References}

Almansa, E., Shcherbakova, A., Jiménez, P., Rodríguez, C., Riera, R., Felipe, B.C., Martín, M.V., Andrade, J.P., Sykes, A.V., 2012. Effects of different tank volumes and feeding regimes on growth, survival and lipid composition of Octopus vulgaris paralarvae. AOUA 2012Global Aquaculture, Prague (Czech Republic), 1st to 5th September 2012

Arai, D., Kuriahara, A., Komi, R., Iwamoto, A., Takeuchi, T., 2008. Effect of feeding various amounts of pacific sandeel flakes on growth, survival and carcass fatty acid composition of common octopus Octopus vulgaris paralarvae. Aquac. Sci. 56 (4), 595-600.

Boletzky, S., 2003. Biology of early life stages in cephalopod mollusks. Adv. Mar. Biol. 44, 143-203.

Campana, S.E., 2001. Accuracy, precision and quality control in age determination, including a review of the use and abuse of age validation methods. J. Fish Biol. 59, 197-242.

Carrasco, J.F., Arronte, J.C., Rodríguez, C., 2006. Paralarval rearing of the common octopus, Octopus vulgaris (Cuvier). Aquac. Res. 37, 1601-1605.

Chang, W.Y.B., 1982. A statistical method for evaluating the reproducibility of age determination. Can. J. Fish. Aquat. Sci. 39, 1208-1210.

Christie, W.W., 1982. Lipid analysis. In: Christie, W.W. (Ed.), in Lipid analysis, second ed. Pergamon Press, Oxford (pp. 17-23; 51-61)

Estefanell, J., Socorro, J., Ramírez, B., Izquierdo, M., Roo, J., 2013. Fatty acid profile in eggs and newly hatched paralarvae of Octopus vulgaris collected from the wild, and afte 1-5 days starvation. Commun. Agric. Appl. Biol. Sci. 78 (4), 119-122.

Estévez, A., Gairin, I., Berger, E., 2009. Wild zooplancton for Octopus vulgaris larval rearing. In: Hendry, C.I., Van Stappen, G., Wille, M., Sorgeloos, P. (Eds.), LARVI 09, Fish \& Shellfish Larviculture Symposium, Special Publication No. 38. European Aquaculture Society, Oostende, pp. 88-91.

Folch, J., Lees, M., Sloane Stanley, G.H., 1957. A simple method for the isolation and purification of total lipids from animal tissues. J. Biol. Chem. 226, 497-509.

Fowler, J., Cohen, L., Jarvis, P., 1998. Practical Statistics for Field Biology. second ed. John Wiley and sons Ltd, West Sussex, England.

Franco-Santos, R.M., Perales-Raya, C., Almansa, E., Detroch, M., Garrido, D., 2015. Beak microstructure analysis as a tool for identifying stress sources during culture of Octopus vulgaris paralarvae. Aquac. Res. (published online, doi: 10.1111/are.12753).

Fuentes, L., Sánchez, F.J., Lago, M.J., Iglesias, J., Pazos, G., Linares, F., 2011. Growth and survival of Octopus vulgaris (Cuvier 1797) paralarvae fed on three Artemia-based diets complemented with frozen fish flakes, crushed zooplankton and marine microalgae. Sci. Mar. 75, 771-777.

Guinot, D., Monroig, Ó., Hontoria, F., Amat, F., Varó, I., Navarro, J.C., 2013. Enriched ongrown Artemia metanauplii actively metabolise highly unsaturated fatty acid rich phospholipids. Aquaculture 412-413, 173-178.

Hernández-López, J.L., Castro-Hernández, J.J., Hernández-García, V., 2001. Age determined from the daily deposition of concentric rings on common octopus (Octopus vulgaris) beaks. Fish. B-NOAA. 99, 679-684.

Iglesias, J., Fuentes, L., 2014. Octopus vulgaris. Paralarval culture. In: Iglesias, J., Fuentes, L, Villanueva, R. (Eds.), In Cephalopod culture. Springer, New York, pp. 427-450.

Iglesias, J., Pazos, G., Fernández, J., Sánchez, F.J., Otero, .J.J., Domingues, P., Lago, M.J., Linares, F., 2014. The effects of using crab zoeae (Maja brachydactyla) on growth and biochemical composition of Octopus vulgaris (Cuvier 1797) paralarvae. Aquacult. Int. 22, 1041-1051.

Itami, K., Izawa, Y., Maeda, S., Nakai, K., 1963. Notes on the laboratory culture of the Octopus larvae. Bull. Jap. Soc. Sci. Fish. 29 (6), 514-520.

Kurihara, A., Okumura, S., Iwamoto, A., Takeuchi, T., 2006. Feeding pacific sandeel enhances DHA level in common octopud paralarvae. Aquac. Sci. 54 (4), 413-420.

Lourenco, S., 2014. Ecology of the Common Octopus Octopus vulgaris (Cuvier, 1797) in the Atlantic Iberian Coast: Life Cycle Strategies Under Different Oceanographic Regimes PhD Thesis Universidade de Lisboa, p. 197.
Monroig, O., Tocher, D.R., Navarro, J.C., 2013. Biosynthesis of polyunsaturated fatty acids in marine invertebrates: recent advances in molecular mechanisms. Mar. Drugs 11, 3998-4018.

Navarro, J.C., Villanueva, R., 2000. Lipid and fatty acid composition of early stages of cephalopods: an approach to their lipid requirements. Aquaculture 183, 161-177.

Navarro, J.C., Villanueva, R., 2003. The fatty acid composition of Octopus vulgaris paralarvae reared with live and inert food: deviation from their natural fatty acid profile. Aquaculture 219, 613-631.

Navarro, J.C., Amat, F., Sargent, J.R., 1993. The lipids of the cysts of freshwater- and marine-type Artemia. Aquaculture 109, 327-336.

Navarro, J.C., Henderson, R.J., McEvoy, L.A., Bell, M.V., Amat, F., 1999. Lipid conversions during enrichment of Artemia. Aquaculture 174, 155-166.

Navarro, J.C., Monroig, O., Sykes, A.V., 2014. Nutrition as a key factor for cephalopod aquaculture. In: Iglesias, J., Fuentes, L., Villanueva, R. (Eds.), Cephalopod Culture. Springer, New York, pp. 77-96.

O'Fallon, J.V., Busboom, J.R., Nelson, M.L., Gaskins, T., 2007. A direct method for fatty acid methyl ester synthesis: application to wet meat tissues, oils, and feedstuffs. J. Anim. Sci. 85, 1511-1521.

Okumura, S., Kurihara, A., Iwamoto, A., Takeuchi, T., 2005. Improved survival and growth in Octopus vulgaris paralarvae by feeding large type Artemia and Pacific sandeel, Ammodytes personatus. Improved survival and growth of common octopus paralarvae. Aquaculture 244, 147-157.

Otero, J., Álvarez-Salgado, X.A., González, Á.F., Gilcoto, M., Guerra, Á., 2009. High-frequency coastal upwelling events influence Octopus vulgaris larval dynamics on the NW Iberian shelf. Mar. Ecol. Prog. Ser. 338, 123-132.

Pecl, G.T., Steer, M.A., Hodgson, K.E., 2004. The role of hatchling size in generating the intrinsic size-at-age variability of cephalopods: extending the Forsythe Hypothesis. Mar. Freshw. Res. 55, 387-394.

Perales-Raya, C., Bartolomé, A., García-Santamaría, T., Pascual-Alayón, P., Almansa, E., 2010. Age estimation obtained from analysis of octopus (Octopus vulgaris Cuvier, 1797) beaks: improvements and comparisons. Fish. Res. 106, 171-176.

Perales-Raya, C., Almansa, E., Bartolomé, A., Felipe, B.C., Iglesias, J., Sánchez, F.J., Carrasco, J.F., Rodríguez, C., 2014. Age validation in Octopus vulgaris beaks across the full ontogenetic range: beaks as recorders of live events in octopuses. J. Shellfish Res. 33 (2), 1-13.

Quintana, D., Márquez, L., Arévalo, J.R., Lorenzo, A., Almansa, E., 2015. Relationships between spawn quality and biochemical composition of eggs and hatchlings of Octopus vulgaris under different parental diets. Aquaculture 446, 206-216.

Reis, D.B., Acosta, N.G., Almansa, E., Navarro, J.C., Tocher, D.R., Monroig, O., Andrade, J.P., Sykes, A.V., Rodríguez, C., 2014. In vivo metabolism of unsaturated fatty acids in Octopus vulgaris hatchlings determined by incubation with ${ }^{14} \mathrm{C}$-labelled fatty acids added directly to seawater as protein complexes. Aquaculture 431, 28-33.

Reis, D.B., García-Herrero, I., Riera, R., Felipe, B.C., Rodríguez, C., Sykes, A.V., Martin, M.V., Andrade, J.P., Almansa, E., 2015. An insight on Octopus vulgaris paralarvae lipid requirements under rearing conditions. Aquac. Nutr. 21, 797-806.

Repolho, T., Baptista, M., Pimentel, M.S., Dionísio, G., Trübenbach, K., Lopes, V.M., Lopes, A.R., Calado, R., Diniz, M., Rosa, R., 2014. Developmental and physiological challenges of octopus (Octopus vulgaris) early life stages under ocean warming. J. Comp. Physiol. B. $184,55-64$.

Roura, Á., González, Á.F., Redd, K., Guerra, Á., 2012. Molecular prey identification in wild Octopus vulgaris paralarvae. Mar. Biol. 159, 1335-1345.

Roura, Á., Doyle, S., Hall, N., Strugnell, J., 2015. Intestinal flora of wild Octopus vulgaris paralarvae and their zooplankton prey: a metagenomic search of "probiotics" for use in aquaculture. "The Digestive Tract of Cephalopods: The Interface Between Ecology and Physiology" A CephsInAction Workshop Under the Aegis of the COST Action FA1301. Lisbon (Cascais, Portugal). 24th November 2015

Roura, A., Álvarez-Salgado, X.A., González, A.F., Gregori, M., Rosón, G., Otero, J., Guerra, A., 2016. Life strategies of cephalopod paralarvae in a coastal upwelling system (NW Iberian Peninsula): insights from zooplankton community and spatio-temporal analyses. Fish. Oceanogr. 25, 241-258.

Seixas, P., Rey-Méndez, M., Valente, L.M.P., Otero, A., 2010a. High DHA content in Artemia is ineffective to improve Octopus vulgaris paralarvae rearing. Aquaculture 300, 156-162

Seixas, P., Otero, A., Valente, L.M.P., Dias, J., Rey-Méndez, M., 2010b. Growth and fatty acid composition of Octopus vulgaris paralarvae fed with enriched Artemia or co-fed with an inert diet. Aquac. Int. 18, 1121-1135.

Socorro, J., Roo, F.J., Izquierdo, M.S., Garcia, J., Carrom, M., 2004. Effect of Different Live Prey Grapsus grapsus Linnaeus, 1758, Plagussia depressa Fabricius, 1775 and Xantho poressa Olivi, 1792 zoeas Over Histology and Biochemical Composition of Common Octopus, Octopus vulgaris Cuvier, 1797 Paralarvae. XI International Symposium on Nutrition and Feeding in Fish. Phuket, Thailand.

Viciano, E., Iglesias, J., Lago, M.J., Sánchez, F.J., Otero, J.J., Navarro, J.C., 2011. Fatty acid composition of polar and neutral lipid fractions of Octopus vulgaris Cuvier, 1797 paralarvae reared with enriched on-grown Artemia. Aquac. Res. 42, 704-709.

Vidal, E.A.G., DiMarco, F.P., Wormuth, J.H., Lee, P.G., 2002. Influence of temperature and food availability on survival, growth and yolk utilization in hatchling squid. B. Mar. Sci. 71, 915-931.

Villanueva, R., 1995. Experimental rearing and growth of planktonic Octopus vulgaris from hatchling to settlement. Can. J. Fish. Aquat. Sci. 52, 2639-2650.

Watanabe, T., Arakawa, T., Kitajima, C., Fukusho, K., Fujita, S., 1978. Nutritional quality of living feed from the viewpoint of essential fatty acids for fish. Bull. Jpn. Soc. Sci. Fish. 44, 1223-1227.

Watanabe, T., Oowa, F., Kitajima, C., Fujita, S., 1980. Relationship between dietary value of brine shrimp Artemia salina and their content of $\omega 3$ highly unsaturated fatty acids. Bull. Jpn. Soc. Sci. Fish. 46, 35-41.

Zar, J.H., 1999. Biostatistical Analysis. fourth ed. Prentice Hall, New Jersey. 